\title{
Triploid Induction in Populus alba $\times$ P. glandulosa by Chromosome Doubling of Female Gametes
}

\author{
By Y. H. LI ${ }^{1)}$, X. Y. KANG ${ }^{\left.1),{ }^{*}\right)}$, S. D. WANG ${ }^{1)}$, Z. H. ZHANG ${ }^{1)}$ and H. W. CHEN ${ }^{1)}$
}

(Received 23 $3^{\text {th }}$ September 2006)

\begin{abstract}
Efficient methods for obtaining unreduced female gametes are needed for triploid induction in Populus alba $\times$ P. glandulosa. A cytological study of MMCs and PMCs meiosis and staminate floral elongation revealed that there was a close association between MMCs meiotic stage and male bud phenology during development under the same environment conditions. Female buds of Populus alba $\times$ P. glandulosa were treated with $0.5 \%$ colchicine solution at the selected meiotic stages based on male bud phenology. The treated buds were pollinated with pollen of $P$. tomentosa. A high rate of unreduced female gametes occurred in late leptotene and pachytene stages of MMC, as evidenced by a relatively higher percentage of triploids in the progeny, when compared to progeny from colchincine application at other meiotic stages. The present results demonstrated that male bud phenology can be used to guide colchicine applications to female buds and cause a more efficient production of triploids.
\end{abstract}

Key words: chromosome doubling, effective treatment stage, female gamete, Populus alba $\times$ P. glandulosa, triploid.

\section{Introduction}

Triploid plants are often characterized by properties of fast growth, large leaves and vigor in comparison with their diploid counterparts. Natural or induced triploid aspen and poplars (Populus L.) can have certain growth and fiber characteristics that are superior to diploid forms (cf. ScHLARBAUM, 1991). The heterosis of triploids in forest trees is usually the result of an increase in ploidy level from fertilization between $\mathrm{n}$ gametes with unreduced (2n) gametes (ZHU et al., 1995). In tree breeding, triploids have been induced by chromosome doubling of pollen in Populus tremula L., P. tremuloides Michx., P. deltoides Bartr. (Johnsson and EkLUndH, 1940; Winton, 1968), P. alba L. (MASHKInA et al., 1989), Hevea brasiliensis Mull. (ZHENG et al., 1983), P. tomentosa Carr. x P. bolleana Lauche P. alba x P. glandulosa (ZHANG and Li, 1992; KANG et al., 1999).

KANG and ZHU (1997) found that $2 n$ pollen germinated later on stigma and pollen tube grew slower than that of $\mathrm{n}$ pollen in $P$. tomentosa Carr. and P. tomentosa $\times$ P. bolleana, which suggested that $2 \mathrm{n}$ pollen does not have competitive advantage over $\mathrm{n}$ pollen and therefore, has less chance of participating in fertilization. In contrast, fertilization of $2 \mathrm{n}$ female gametes by $\mathrm{n}$ pollen would have the potential to create greater numbers of

\footnotetext{
1) Key Laboratory for Genetics and Breeding of Forest Trees and Ornamental Plants, Ministry of Education, Beijing Forestry University, P. O. Box 118, 100083, Beijing, China.

*) Corresponding author: XIANGyang KANG. Telephone: 86-1062336104, E-mail: kangxy@bju.edu.cn.
}

triploids. Triploids were obtained by chromosome doubling of female gametes from Morus alba L. (DwIVEDI et al., 1989) and P. tomentosa $\times$ P. bolleana (LI et al., 2001). The incidence of triploid poplars, however, was low and consistent results were difficult to obtain in repeated experiments. These studies identified the need to correlate meiotic stage of megaspore mother cells (MMCs) with colchicine treatment. Unfortunately, MMCs meiosis can only be observed through paraffin sectioning, which is a slow and destructive process. This study was conducted to examine the feasibility of an alternative, non-destructive approach to induce unreduced female gametes in $P$. alba $\times$ P. glandulosa. We will attempt to correlate meiosis in pollen mother cells (PMCs) with male bud phenological development and in turn correlate male bud phenology with MMCs meiosis. We will then study the effects of colchicine treatments at different MMCs meiotic stages on ploidy, as indicated percentage of triploid progeny.

\section{Material and Methods \\ Plant materials}

In the present study, cuttings from sexually mature trees of $P$. alba $\times$. glandulosa, which is native to Korea, and $P$. tomentosa, a timber species native to China, were. In early January 2004, floral branches were cut and hydroponically cultured in a greenhouse with day and night temperatures around $20^{\circ} \mathrm{C}$ and $10^{\circ} \mathrm{C}$, respectively.

\section{Phenological observations}

The morphological stage of male and female catkins were observed after floral branches were cultured in the greenhouse. The ratio of unfolded catkin/bud were measured every $12 \mathrm{~h}$, from 5 to 8 days in greenhouse conditions.

\section{Meiosis of MMCs and PMCs}

Observations of MMCs and PMCs meiosis were periodically conducted after the female and male floral branches of $P$. alba $\times$ P. glandulosa were cut and cultured in greenhouse. After $14 \mathrm{~h}$ in culture, 3-4 floral buds were collected from the female and male floral branches every $3 \mathrm{~h}$ until the ninth day. The number of floral buds collected was about 702. The collected female and male floral buds were fixed in FAA (18:1:1, ethy1 alcohol: formaldehyde: acetic acid) and Carnoy (3:1 ethy1 alcohol: acetic acid) respectively, then stored at $4^{\circ} \mathrm{C}$. Meiosis was observed in PMCs excised from anthers of the fixed floral buds. The PMCs were squeezed out of the anthers into a drop of aceto-carmine $(2 \%)$ and squashed. 
Pistillate flowers at various developmental stages were removed from catkins, dehydrated by consecutive immersion in $70 \%, 85 \%, 95 \%$ and $100 \%$ ethanol $(2 \mathrm{~h}$ for each immersion), embedded in paraffin (MA et al, 2002) sectioned between $8-10 \mu \mathrm{m}$, and dyed with $0.5 \%$ hematoxylin. The preparations were observed under an Olympus BX51 microscope and photographed. At least 3-4 buds were sampled and 50-60 ovules were checked for each stage of development.

\section{Chromosome doubling of female gametes}

After associating MMCs and PMCs meiotic stages with male bud development, eight female floral buds of $P$. alba $\times$ P. glandulosa were immersed in a $0.5 \%$ solution of colchicine (Li et al., 2001) for $24 \mathrm{~h}$ with the exception of the controls (four female floral buds). Colchicine treatments were initiated at $140 \mathrm{~h}, 152 \mathrm{~h}, 164 \mathrm{~h}, 176 \mathrm{~h}$ and $188 \mathrm{~h}$ respectively after the floral branches were cultured in greenhouse ranging from tetrad to two celled pollen stage of PMCs during each meiotic stage of MMCs (leptotene, late leptotene, pachytene, diplotene, diakinesis and metaphase I). Pollination was conducted with $P$. tomentosa when the stigma was at the optimal receptive stage, as evidenced by a large amount of secretion After pollination, the female floral branches were further cultured in water until seeds matured and were harvested, approximately 2-3 weeks. Subsequently the seeds were sown in soil for each treatment and control. After 2 months the seedlings were transplanted to field.

\section{Chromosome counts of progeny}

Chromosome counts of two-year-old hybrid progenies were determined using shoot tips prepared according to the protocol developed by KANG (1996) and stained with Giemsa for 10 min at room temperature.

\section{Statistics analysis}

The ratio of triploids/seedlings was calculated in each colchicine treatment. The meiotic stage of MMCs was determined by the percentage of MMCs meiotic stage in each floral development. Pearson's correlation coefficient was used to evaluate correlation between the ratio of triploids/seedlings and the percentage of MMCs meiotic stage. Statistical analysis were performed by one-way analysis of correlation coefficient using Data processing system 7.55 software(DPS7.55). Statiscial significant difference was assumed when $\mathrm{P}$ value was $<0.05$.

\section{Results}

Association of MMCs and PMCs of P. alba $\times$ P. glandulosa

Cytological observations of MMCs and PMCs meiosis revealed that there was a close association between MMCs meiotic stage and male bud phenology during development (Table 1). After $140 \mathrm{~h}$ in culture, when the meiosis stage of PMCs developed into tetrads, the meiosis stage of MMCs of $P$. alba $\times$ P. glandulosa was just beginning leptotene, and $1 / 4$ pistillate catkin and $1 / 2$ staminate catkin were protruded from squama respectively. After $164 \mathrm{~h}$ in culture, the meiosis stage of MMCs was in pachytene stage, and $3 / 4$ staminate catkin and $1 / 2$ pistillate catkin were protruded from squama respectively. Within the female buds in a pistillate catkin, most MMCs were synchronized meiotically. Table1 also showed the association between the morphological characteristics of catkins and the stage of meiosis.

\section{Chromosome counts}

Table 2 presents the results obtained in terms of number of seedlings and percentage of triploid poplars

Table 1. - Association of MMCs and PMCs of P. alba x P. glandulosa.

\begin{tabular}{|c|c|c|c|c|}
\hline \multirow{3}{*}{$\begin{array}{c}\begin{array}{c}\text { Hours } \\
\text { after } \\
\text { culture }^{\mathrm{a}}\end{array} \\
140 \mathrm{~h}\end{array}$} & \multicolumn{2}{|c|}{$\begin{array}{l}\text { The meiosis stages of PMCs and the male } \\
\text { gamete development }\end{array}$} & \multicolumn{2}{|c|}{ The meiosis stages of MMCs } \\
\hline & The meiosis stage & $\begin{array}{c}\text { unfolded } \\
\text { catkin/bud }^{\mathrm{b}}\end{array}$ & The meiosis stage & $\begin{array}{l}\text { unfolded } \\
\text { catkin/bud }\end{array}$ \\
\hline & Tetrad & $1 / 2$ & Leptotene, late leptotene & $1 / 4$ \\
\hline $152 \mathrm{~h}$ & $\begin{array}{l}\text { Tetrad, mid-uninucleate } \\
\text { microspore }\end{array}$ & $1 / 2$ & Late leptotene & $1 / 3$ \\
\hline $164 \mathrm{~h}$ & $\begin{array}{l}\text { Pollen with a single } \\
\text { nuclear } \\
\text { adjacent to cell wall }\end{array}$ & $3 / 4$ & Late leptotene, pachytene & $1 / 2$ \\
\hline $176 \mathrm{~h}$ & $\begin{array}{l}\text { Pollen with a single } \\
\text { nuclear } \\
\text { adjacent to cell wall }\end{array}$ & $>3 / 4$ & Diplotene, pachytene & $1 / 2$ \\
\hline $188 \mathrm{~h}$ & binucleate pollen & $>3 / 4$ & $\begin{array}{c}\text { Late leptotene, pachytene } \\
\text { diakinesis, } \\
\text { metaphase I. }\end{array}$ & $>1 / 2$ \\
\hline
\end{tabular}

\footnotetext{
a Hours after culture indicates the collection time of female buds.

${ }^{\mathrm{b}}$ unfolded catkin/bud indicates the ratio of unfolded catkin/bud.
} 

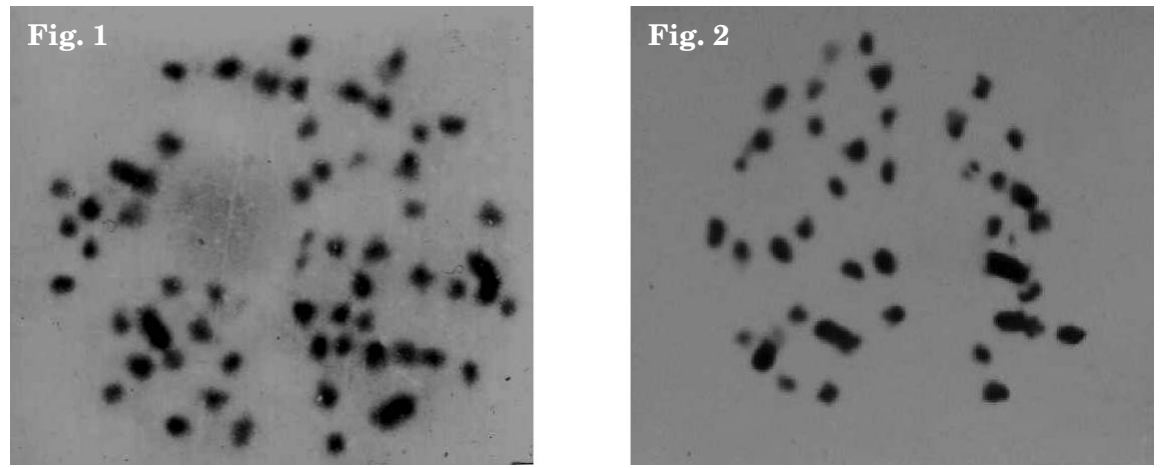

Figure 1. - Chromosomes of triploid poplars. $(2 \mathrm{n}=3 \mathrm{x}=57)$.

Figure 2. - Chromosomes of diploid hybrid progeny. $(2 \mathrm{n}=2 \mathrm{x}=38)$.

among the hybrid progenies. A total of 12 seedlings were identified as triploid poplars among 354 colchicine treatment hybrid progenies (Figure 1), while the remaining seedlings were diploid (Figure 2). Triploids were obtained in every colchicine treatment. There were no triploids obtained in control treatment. Guided by the association between MMCs meiotic stage and male bud phenology during development, the female buds were treated with colchicine solution at the meiotic stage of late leptotene (100\% MMCs). Two triploids were identified, accounting for $16.7 \%$ of the 12 survived two-yearold seedlings. When treatment occurred at pachytene (61.5\% MMCs) two triploid poplars were produced among 87 seedlings total. Later pachytene treatments (75\% MMCs) produced three triploid poplars among 25 seedlings total. Treatment at diakinesis $(64.7 \% \mathrm{MMCs})$ produced four triploids, which represented $5.0 \%$ of 80 hybrid progenies. Overall, Table 2 shows that the high percentage of triploids were obtained when the meiosis stage of most MMCs developed into late leptotene and pachytene stage.

Statistical analysis indicated that the rate of triploids was positive correlated with the late leptotene and pachytene stage of MMCs meiotic stage, especially in diplotene stage, while the rate of triploids had negative correlation coefficient with the leptotene, diakinesis and metaphase I stage of MMCs meiotic stage. There was not statistically significant correlation between the rate of triploids and percentage of MMCs meiotic stage $(\mathrm{r}=0.8783, \mathrm{p}=0.05)$.

\section{Discussion}

The high rate of triploids was primarily obtained in MMC late leptotene and pachytene stages and were associated with PMC and male bud phenology develop-

Table 2. - Triploid induction in P. alba $\times$ P. glandulosa by the chromosome doubling of female gamete.

\begin{tabular}{|c|c|c|c|c|c|c|c|c|c|c|}
\hline \multirow{2}{*}{$\begin{array}{l}\text { Hours } \\
\text { after } \\
\text { culture }^{\mathrm{c}}\end{array}$} & \multicolumn{6}{|c|}{ The meiosis stages of MMCs(\%) } & \multirow{2}{*}{ seeds } & \multirow{2}{*}{ seedlings } & \multirow{2}{*}{ triploids } & \multirow{2}{*}{$\begin{array}{c}\text { Rate of } \\
\text { triploids } \\
(\%)\end{array}$} \\
\hline & Leptotene & $\begin{array}{c}\text { Late } \\
\text { leptotene }\end{array}$ & Pachytene & Diplotene & Diakinesis & $\begin{array}{c}\text { Metaphas } \\
\text { e I }\end{array}$ & & & & \\
\hline $140 \mathrm{~h}$ & 33.3 & 66.7 & 0 & 0 & 0 & 0 & 712 & 150 & 1 & 0.7 \\
\hline $152 \mathrm{~h}$ & 0 & 100 & 0 & 0 & 0 & 0 & 476 & 12 & 2 & 16.7 \\
\hline $164 h$ & 0 & 38.5 & 61.5 & 0 & 0 & 0 & 876 & 87 & 2 & 2.3 \\
\hline $176 \mathrm{~h}$ & 0 & 0 & 75.0 & 25.0 & 0 & 0 & 731 & 25 & 3 & 12.0 \\
\hline $188 \mathrm{~h}$ & 0 & 3.9 & 17.7 & 0 & 64.7 & 13.7 & 215 & 80 & 4 & 5.0 \\
\hline Control $^{\mathrm{d}}$ & - & - & - & - & - & - & 285 & 142 & 0 & 0 \\
\hline Total & - & - & - & - & - & - & 3295 & 496 & 12 & - \\
\hline
\end{tabular}

${ }^{\mathrm{c}}$ Hours after culture indicates the collection time of female buds and the treatment time of female buds.

d Control: no colchicine treatment. 
ment of $P$. alba $\times$ P. glandulosa. Although not statistically significant, the correlation trends suggests that a relatively higher frequency of unreduced $2 n$ female gametes were induced in late leptotene and pachytene. It may be the induction of triploidy is so low that the statistical procedures used in this study would not show significance at the common error level of 0.05. Future studies that generate large number of seeds are needed to confirm the trends.

The high percentage of triploids (16.7\%) obtained in the present study was higher than that of triploids $(3.8 \%)$ induced by the unreduced pollen in Populus (KANG et al., 2000). Therefore, colchicine induction of $2 \mathrm{n}$ female gametes using the association of MMCs with male bud phenology as a guide appears to be an efficient approach for creation of triploids in P. alba $\times$ P. glandulosa. Moreover, this approach avoids subjection of female floral buds to high temperatures and daily applications of colchicine used in previous studies (LI et al, 2001).

\section{Acknowledgements}

The authors thank Dr. G. HAZENBERG for critical reading of the manuscript. The research was financially supported by the State Forestry Administration of China (1999-12) and the National Natural Science Foundation of China (30671708).

\section{References}

Dwivedi, N. K., N. Suryanarayana, A. K. Sikdar, B. N. Susheelamma and M. S. Jolly (1989): Cytomorphological studies in triploid mulberry evolved by diploidization of female gamete cells. Cytologia 54: 13-19.

Johnsson, H. and C. EkLUNDH (1940): Colchicine treatment as a method in breeding hardwood species. Svensk Papp Tidn 43: 373-377.
KANG, X. Y. and Z. T. ZHU (1997): A study on the 2n pollen vitality and germinant characteristics of white poplars. Acta Botanica Yunnanica 19 (4): 402-406.

KANG, X. Y. (1996): Chromosome count and shape of poplar. Journal of Gansu Agricultural University 31(1): 67-70.

KANG, X. Y., Z. T. ZHU and H. B. LIN (1999): Study on the effective treating period for pollen chromosome doubling of Populus tomentosa $\times$ P. bolleana. Scientia Silvae Sinicae 35(4): 21-24.

KANG, X. Y., Z. T. ZHU and H. B. LIN (2000): Radiosensitivity of different ploidy pollen in poplar and its application. Acta Genetica Sinica 27(1): 78-82.

Li, Y., Z. T. ZHU, Y. T. TIAN, Z. Y. Zhang and X. Y. KANG (2001): Studies on obtaining triploids by colchicine treating female flower buds of white poplars. Scientia Silvae Sinicae 37(5): 68-74.

Mashkina, O. S., L. M. Burdaeva, M. M. Belozerova and L. N. V'YUNOVA (1989): A method of inducing diploid pollen in woody species. Lesovedenie 1: 19-25 (in Russian).

MA, S.-M., X.-L. YE, N.-X. ZHAO and C.-Y. LIANG (2002): Embryological studies on facultative apomixis in apluda mutica (Gramineae). Acta Botanica Sinica 44(3): 259-263.

Schlarbaum, S. E. (1991): Cytogenetics of forest tree species. In: TsuchiYA, T. and P. K. GuPTA, eds. Chromosome engineering in plant genetics and breeding. Vol. Elsevier Science Publ., Netherlands, p. 593-618.

WinTON, L. L. (1968): Fertilization in forced quaking aspen and cottonwood. Silvae Genetica 17(1): 20-21.

ZHANG, Z. Y. and F. L. LI (1992): Studies on chromosome doubling and triploid breeding of white poplar (_)-The techniques of the pollen chromosome doubling, Journal of Beijing Forestry University, vol. 14, Supp. 3: 52-5.

Zheng, X. Q., X. S. Zeng, X. M. Chen and G. L. Yang (1983): A new method for inducing triploid of Hevea brasiliensis. Chinese Journal of Tropical Crops 4(1): $1-4$.

ZHU, Z. T., H. B. LiN and X. Y. KANG (1995): Studies on all triploid breeding of Populus tomentosa B301 clones. Scientia Silvae Sinicae 31(6): 499-505. 